PM0-31 RAPIDITY OF ULCERATIVE COLITIS SYMPTOM IMPROVEMENTS DURING FILGOTINIB INDUCTION: PHASE 2B/3 SELECTION STUDY POST-HOC ANALYSIS

${ }^{1}$ Ben Morison*, ${ }^{2}$ Silvio Danese, ${ }^{3}$ Toshifumi Hibi, ${ }^{4}$ Timothy E Ritter, ${ }^{5}$ Jason B Dinoso, ${ }^{5}$ Jeremy Hsieh, ${ }^{5}$ Chohee Yun, ${ }^{5}$ Jie Zhang, ${ }^{5}$ Sally Zhao, ${ }^{6}$ Edward V Loftus, ${ }^{7}$ Gerhard Rogler. ${ }^{1}$ Norfolk and Norwich University Hospital, Norwich, UK; ${ }^{2}$ Humanitas Clinical and Research Center, IRCCS and Humanitas University, Italy; ${ }^{3}$ Kitasato Institute Hospital, Kitasato University, Japan; ${ }^{4} G$ I Alliance, Southlake, USA; ${ }^{5}$ Gilead Sciences, Inc., Foster City, USA; ${ }^{6}$ Mayo Clinic College of Medicine, Rochester, USA; 7 University Hospital of Zurich, University of Zurich, Switzerland

\subsection{6/gutjnl-2021-BSG.170}

Introduction Filgotinib (FIL) is a preferential Janus kinase 1 inhibitor. SELECTION was a phase $2 b / 3$ randomised, doubleblind, placebo (PBO)-controlled trial to evaluate FIL for the treatment of moderately to severely active ulcerative colitis (UC) (NCT02914522). The aim of this post hoc analysis was to assess the speed of improvement in patient-reported outcomes (PROs) during FIL treatment.

Methods Eligible patients who were biologic-naïve or -experienced were enrolled in induction study A or induction study $\mathrm{B}$, respectively. In each study, patients were randomised 2:2:1 to receive FIL $100 \mathrm{mg}$, FIL $200 \mathrm{mg}$ or PBO once daily orally for 10 weeks. In this post hoc analysis, data from daily patient diaries up to day 15 of induction, including Mayo stool frequency subscores (SF; range, 0 [normal] to $3[\geq 5$ stools/day more than normal]) and rectal bleeding subscores (RB; range, 0 [no blood] to 3 [passing blood alone]), were used to evaluate the proportion of patients achieving predefined subscores or subscore reductions.

Results Induction studies A and B comprised 659 and 689 patients, respectively. Baseline characteristics were similar across treatment groups. In induction study $\mathrm{A}$, more patients treated with FIL $200 \mathrm{mg}$ vs $\mathrm{PBO}$ reported a reduction in SF of $\geq 1$ from baseline as early as day 6 (FIL $200 \mathrm{mg}, 35.8 \%$; PBO, $20.6 \%, p<0.01$ ), and a reduction in $\mathrm{RB}$ of $\geq 1$ from baseline as early as day 4 (FIL $200 \mathrm{mg}, 36.9 \%$; PBO, 23.7\%; $p<0.01$ ). In induction study $\mathrm{B}$, more patients treated with FIL $200 \mathrm{mg}$ vs $\mathrm{PBO}$ reported a reduction in $\mathrm{SF}$ of $\geq 1$ from baseline as early as day 2 (FIL $200 \mathrm{mg}, 21.6 \%$; PBO, 12.1\%; $p<0.05$ ) and a reduction in $\mathrm{RB}$ of $\geq 1$ from baseline as early as day 3 (FIL $200 \mathrm{mg}, 29.5 \%$; PBO, 17.6\%; $p<0.01$ ). More patients receiving FIL $200 \mathrm{mg}$ vs $\mathrm{PBO}$ achieved the composite score of $\mathrm{RB}=0$ and $\mathrm{SF} \leq 1$ as early as day 9 in induction study A (FIL $200 \mathrm{mg}, 18.8 \%$; PBO, 9.5\%, $p<0.05$ )and as early as day 7 in induction study B (FIL $200 \mathrm{mg}, 10.7 \%$; PBO, 4.2\%, $p<0.05$ ). Conclusions In this post hoc analysis of induction study data from SELECTION, improvements in SF and RB were observed within the first week of therapy with FIL $200 \mathrm{mg}$, compared with PBO. These data demonstrate that FIL $200 \mathrm{mg}$ has rapid onset of action, as assessed by PROs, in both biologic-naïve and biologic-experienced patients with moderately to severely active UC.

\section{PMO-32 PREGNANCY OUTCOMES AFTER STOMA SURGERY FOR IBD: THE RESULTS OF A MULTI-CENTRE RETROSPECTIVE AUDIT}

${ }^{1}$ Sue Blackwell ${ }^{*}{ }^{2}$ Christian Selinger, ${ }^{3}$ Matthew Brookes, ${ }^{4}$ Nicola Fearnhead, Steering Group PAPooSE, Collaborators PAPooSE. 'Patient Chief Investigator, Liverpool, UK; ${ }^{2}$ Leeds Teaching Hospitals NHS Trust, Leeds, UK; ${ }^{3}$ Royal Wolverhampton Hospital NHS Trust, Wolverhampton, UK; ${ }^{4}$ Cambridge University Hospitals NHS Trust, Cambridge, UK
Introduction There is a paucity of data on pregnancies in women with stomas due to Inflammatory Bowel Disease (IBD) with the existing literature focused on fertility and conception rather than patient experience and outcome of pregnancy after stoma surgery. The aim of this study was to assess stoma, IBD, obstetric and neonatal outcomes in pregnant patients with IBD and a stoma

Methods This was a multi-centre retrospective audit carried out in 15 UK hospitals (11 specialist University Teaching Hospitals and 4 District General hospitals). Female patients who had a confirmed diagnosis of IBD who had experienced pregnancy following stoma formation (ileostomy or colostomy) since 2014 were eligible for inclusion in the study. We excluded patients with stomas for reasons other than IBD and those who had their stoma reversed prior to pregnancy. Pregnancy, stoma and neonatal outcomes were elicited from routinely collected hospital records.

Results Data on 82 pregnancies from 77 patients (mean age 31.4 years, $60.9 \%$ Crohn's Disease, $35 \cdot 4 \%$ Ulcerative Colitis, $3 \cdot 6 \%$ IBD-U) were included. Stoma types included Ileostomy in $72(88 \%)$ and colostomy in $10(12 \%)$ women. There was one reported miscarriage, one still birth and 80 live births. Delivery occurred in 58 cases by caesarean section (CS), of which 44 were performed electively and 14 as emergency CS. The overall CS rate was $73 \%$. Premature delivery before week 37 occurred in $19 \%$ and birth weight $<2500 \mathrm{~g}$ in $17 \%$. Significant stoma related complications occurred during $22(27 \%)$ pregnancies and included stoma prolapse in 9 cases (2 required surgery), parastomal hernias in 3 cases ( 2 required surgery) and small bowel obstructions in 7 of cases (3 required surgery).

Conclusions To our knowledge this retrospective audit is the only comprehensive modern report of pregnancy outcomes following stoma surgery for Inflammatory Bowel Disease. By examining 82 pregnancies in 77 women, we have shown that women with a stoma due to IBD surgery have higher rates of caesarean section, are more likely to deliver preterm and have low birth weight babies compared to the general population. They also face a significant risk of major stoma complications. This study suggests patients with IBD and a stoma should be counselled appropriately with regards the method of delivery and the potential complications of pregnancy with regards to having a stoma.

\section{PMO-33 INFLIXIMAB BIOSIMILAR SWITCHING - CAN YOU SWITCH MORE THAN ONCE?}

Nina Taherzadeh*, Dev Kataery, Charles Murray, Tina Shah. Royal Free London NHS Foundation Trust, London, UK

\subsection{6/gutjnl-2021-BSG.172}

Introduction With the increasing availability of biosimilar infliximab (IFX) products, there is a drive to lower costs without compromising patient outcomes. Switching from originator to biosimilar biologics has been shown to be safe and effective in patients with inflammatory bowel disease (IBD), but less is known about the safety and efficacy of switching between multiple biosimilar brands. The aim of this study was to report the outcomes of patients undergoing a biosimilar IFX switch for the first time (Remsima ${ }^{\circledR}$ to Zessly ${ }^{\circledR}$ ) compared to those patients that have undergone a previous originator to 
biosimilar IFX switch (Remicade ${ }^{\circledR}$ to Remsima ${ }^{\circledR}$ to Zessly ${ }^{\circledR}$ ), in a real-life IBD cohort.

Methods A retrospective cohort study was carried out, and eligible patients were identified through a in-house database. All patients on treatment with $\operatorname{Remsima}^{\circledR}$ were eligible for the switch to Zessly ${ }^{\circledR}$. The primary aim of the study was to assess the clinical outcomes (in terms of continuation of therapy, loss of response and achievement of remission allowing cessation of biologic therapy) between the two patient groups, over a six month period following their switch to Zessly ${ }^{\circledR}$. Secondary outcomes measured were infusion reactions and rates of hospitalisation for an acute flare.

Results A total of 147 patients were eligible for and underwent the biosimilar-to-biosimilar switch; median age was 41 (IQR 28-56), 95 (64.6\%) were male, and 107 (72.8\%) had Crohn's Disease. Of the total cohort, 96 (65.3\%) were undergoing their first biosimilar switch (Remsima ${ }^{\circledR}$ to Zessly ${ }^{\circledR}$ ), whereas $51(34.7 \%)$ were undergoing their second biosimilar switch (Remicade ${ }^{\circledR}$ to Remsima ${ }^{\circledR}$ to Zessly ${ }^{\circledR}$ ). In those with one versus two biologic switches, there were no differences seen in the number of patients being able to continue Zessly ${ }^{\circledR}$ $(79.2 \%$ vs $80.4 \%, \mathrm{p}=0.861)$, loss of response to Zessly ${ }^{\circledR}$ $(11.5 \%$ vs $5.9 \%, p=0.273)$, or achievement of remission on Zessly ${ }^{\circledR}$ resulting in cessation of therapy $(1.0 \%$ vs $0 \%$, $\mathrm{p}=0.465)$. None of the patients from either group experienced any infusion-related reactions. There was no difference in hospitalisation in the six months following biologic switch (3.1\% vs $2.0 \%, \mathrm{p}=0.680)$.

Conclusions This real-life, single centre, short-term evaluation demonstrated that switching between biosimilar IFX brands appears to be as safe and effective as switching from originator to biosimilar IFX. A larger randomised-controlled study would be needed to confirm both the safety and effectiveness of switching between multiple biosimilar brands to substantiate the results of this evaluation.

\section{PMO-34 IBD DISK TOOL FOR EVALUATION OF PATIENT REPORTED OUTCOMES IN PATIENTS SUFFERING FROM RECURRENT POUCHITIS}

Sharafaath Shariff*, Neel Sharma, Rachel Cooney. Queen Elizabeth Hospital Birmingham, Birmingham, UK

\subsection{6/gutjnl-2021-BSG.173}

Introduction Although the primary treatment for UC is medical, approximately $20 \%$ to $30 \%$ of patients with Ulcerative Colitis (UC) will undergo proctocolectomy. (1) Ileal Pouch anal anastomosis (IPAA) surgery is an option for patients to restore gut continuity post proctocolectomy. The majority of patients will develop acute pouchitis and over time up to $25 \%$ develop chronic pouchitis. (2) The IBD-Disk was adapted from the Inflammatory Bowel Disease -Disability Index (IBDDI) as a tool to capture patient's functional status for Health Care Professionals (HCPs) to review. (3) We report the patient use and applicability of the IBD-Disk in pouchitis patients at a tertiary IBD Centre in the West Midlands.

Methods 11 patients attending the pouch clinic at a tertiary IBD centre in West Midlands were interviewed over a 6 month period (December 2020 to May 2021) with regards to their functional disability using the IBD Disk. In addition they were asked to provide their insights as to what additional symptoms should be included as part of the Disk. This element was deemed crucial as the original IBD Disk did not include patient involvement in its design.

Results 9/11 (82\%) were male. Age ranged from 35 to 73 years, mean 51 years. 8/11 (72\%) were White British and the remaining were Asian. Mean pouch duration was 18 years, range 3 to 30 years. Except for 1 patient, all others had a single IPAA procedure. 5/11 (45\%) had a single course of antibiotics with a maximum duration of a month, namely Ciprofloxacin or Metronidazole.

Out of the 10 components of the IBD Disk, lack of energy and feeling tired was the most important for our patients with a mean score of 7.3/10 followed by abdominal pain with a mean score of 6.7 and difficulty sleeping with a mean score of 6.4. The lowest scoring domains were education and work, mean score 3.5 followed by interpersonal interactions (3.7).

Additional symptoms that were important to this patient group but not included in IBD disk were mental wellbeing, rectal bleeding and fever. Incontinence for liquid stools also proved to be an important concern to $82 \%$ (9/11) of patients. Further aspects of concern comprised needing to wear a pad or plug and the effect of food on their pouch symptoms (54.5\%) (6/11).

Conclusions Currently there are no validated patient reported outcome (PRO) tools available to assess patients suffering from pouchitis. The IBD Disk was used to assess its potential in our pouchitis patients. Its limitation however is that it is not designed for pouchitis specifically and was not developed with patient involvement. This work would suggest however that IBD disk may be adaptable for use in this patient group by the addition of the following symptoms- mental well being, rectal bleeding, fever and incontinence.

\section{REFERENCES}

1. Leijonmarck CE, Persson PG, Hellers G. Factors affecting colectomy rate in ulcerative colitis: an epidemiologic study. Gut. 1990 Mar;31(3):329-33. doi: 10.1136/ gut.31.3.329. PMID: 2323599; PMCID: PMC1378277.

2. Darrell S. Pardi, MD, Geert D'Haens, MD, PhD, Bo Shen, MD, Simon Campbell, MD, Paolo Gionchetti, MD, PhD, Clinical Guidelines for the Management of Pou chitis, Inflammatory Bowel Diseases, Volume 15, Issue 9, 1 September 2009, Pages 1424-1431, https://doi.org/10.1002/ibd.21039

3. Ghosh S, Louis E, Beaugerie L, Bossuyt P, Bouguen G, Bourreille A, Ferrante $M$, Franchimont D, Frost K, Hebuterne X, Marshall JK, O'Shea C, Rosenfeld G, Williams C, Peyrin-Biroulet L. Development of the IBD Disk: A Visual Self-administered Tool for Assessing Disability in Inflammatory Bowel Diseases. Inflamm Bowe Dis. 2017 Mar;23(3):333-340. doi: 10.1097/MIB.0000000000001033. PMID: 28146002; PMCID: PMC5319390.

\section{PM0-35 UK NATIONAL AUDIT ON DIAGNOSIS AND MANAGEMENT OF COLITIS IN PATIENTS WITH PRIMARY SCLEROSING CHOLANGITIS}

${ }^{1}$ Evangelia Fatourou*, ${ }^{2}$ Dominic King, ${ }^{3}$ Sarah Hyde, ${ }^{4}$ Martine Walmsley, ${ }^{1}$ Graeme Alexander, ${ }^{2}$ Palak Trivedi, ${ }^{3}$ Simon Rushbrook, 'Douglas Thorburn, Investigating Contributors UK PSC. 'Sheila Sherlock Liver Centre and UCL Institute for Liver and Digestive Health, Royal Free Hospital, London, United Kingdon; ' University Hospitals Birmingham, Birmingham, UK; ${ }^{3}$ Department of Hepatology, Norwich Medical School, University of East Anglia, Norwich, UK; ${ }^{4}$ PSC Support, Oxford, UK

\subsection{6/gutjnl-2021-BSG.174}

Introduction The increased risk of colorectal cancer in patients with primary sclerosing cholangitis (PSC) and inflammatory bowel disease (IBD) justifies an enhanced surveillance strategy with annual colonoscopy and dye spray or protocol biopsies. As symptoms are frequently mild in PSC-IBD colitis can be missed unless colonoscopy and biopsies are undertaken at 